\title{
Los Mayores y el territorio de Jenoy (Pasto, Colombia): quehacer etnográfico y etnoliteratura de resistencia ${ }^{1}$
}

\author{
Franco Ceballos Rosero ${ }^{2}$ \\ Universidad Cooperativa de Colombia \\ franco.ceballosr@campusucc.edu.co \\ Recibido: 20 de julio de 2017 \\ Aceptado: 18 de junio de 2018 \\ Disponible en linea: 28 de diciembre de 2018
}

\footnotetext{
1 Artículo de reflexión derivado de los proyectos: "Reconceptualización del concepto de persona y persona natural desde la perspectiva político-jurídica de los derechos de la naturaleza para la interpretación, enseñanza y uso alternativo del derecho" y "Litigio estratégico para el establecimiento de los derechos de la naturaleza en el ordenamiento jurídico colombiano", Facultad de Derecho, Universidad Cooperativa de Colombia (2017-2018).

2 Abogado y Magister en Etnoliteratura, Universidad de Nariño. Docente Investigador, Facultad de Derecho, Universidad Cooperativa de Colombia, sede Pasto.
} 


\title{
Los Mayores y el territorio de Jenoy \\ (Pasto, Colombia): quehacer etnográfico y etnoliteratura de resistencia
}

\section{Resumen}

El presente documento, desde un quehacer etnográfico indisciplinado, de largo aliento y solidario, presenta una mirada del proceso de reconstrucción identitaria y territorial del pueblo originario de Jenoy (Colombia), trece años después de la declaratoria como zona de desastre del territorio aledaño al volcán Galeras en 2005 (Decreto 4106), y la orden de reubicación de la población humana asentada en la zona de amenaza volcánica alta en 2008 (Decreto 3905); todo ratificado por la jurisprudencia constitucional en 2015 (Sentencia T-269), a pesar de la legitima oposición comunitaria (Art. 16, Ley 21 de 1991). La construcción del documento se propone desde una etnografía literaria o etnoliteratura, fundamentada en la memoria oral y territorial de los Mayores. Son herramientas suyas el diálogo, la solidaridad y los caminos.

Palabras clave: memoria; pueblos originarios; etnografia; etnoliteratura; resistencia; Jenoy (Colombia)

\section{The Elderly and the Territory of Jenoy \\ (Pasto, Colombia): Ethnography and Ethnoliterature of Resistance}

\begin{abstract}
The present article is the result of an undisciplined, long-lasting and supportive ethnographic work that aims to examine the process of identity and territorial reconstruction of the native people of Jenoy (Colombia), thirteen years after being declared a disaster area located in the territory adjacent to the Galeras volcano in 2005 (Decree 4106), and receiving the order to relocate the population settled in a zone of high volcanic risk in 2008 (Decree 3905); both decisions being subsequently ratified by the constitutional jurisprudence in 2015 (Sentence T-269) despite the legitimate community opposition (Article 16, Law 21 of 1991). The construction of the document is proposed from a literary ethnography or ethnoliterature, based on the oral and territorial memory of the elderly native people. For this purpose, the work is oriented towards dialogue, solidarity and the search for new paths.
\end{abstract}

Keywords: memory; indigenous peoples; ethnography; ethnoliterature; resistance; Jenoy (Colombia)

\section{Os idosos e o território de Jenoy (Pasto, Colômbia): afazer etnográfico e etnoliteratura de resistência}

Resumo

O presente documento, desde um afazer etnográfico indisciplinado, de longo alento e solidário, apresenta um olhar do processo de reconstrução identitária e territorial do povo originário de Jenoy (Colômbia), treze anos após a declaratória como uma área de desastre do território adjacente ao vulcão Galeras em 2005 (Decreto 4106), e a ordem de relocalização da população humana assentada na zona de ameaça vulcânica alta em 2008 (Decreto 3905); todo ratificado pela jurisprudência constitucional em 2015 (Sentencia T-269) a pesar da legítima oposição comunitária (Art. 16, Lei 21 de 1991). A construção do documento propõe-se desde uma etnografia literária ou etnoliteratura; fundamentada na memória oral e territorial dos idosos. Diálogo, solidariedade e estradas são suas ferramentas.

Palavras-chave: memória; povos originários; etnografia; etnoliteratura; resistência; Jenoy (Colômbia) 


\section{Introducción}

E1 28 de enero de 2008, con el liderazgo de los Mayores del territorio de Jenoy, parte de su población nombró y posesionó autoridades tradicionales étnicas bajo la figura del Cabildo (figura 1), apoyados en la memoria oral, territorial y archivística que prueba la existencia de estas hasta 1950, cuando fueron disueltas con la declaratoria de inexistencia de su Resguardo de origen colonial, por parte del Ministerio de Agricultura, con la Resolución 25. ${ }^{3}$ Ese día, Don José Francisco Yaqueno empuñó la vara de justicia del último Gobernador indígena, Don Darío Criollo, para plantarse frente al gobierno nacional de forma oficial y rechazar las medidas tomadas a raíz de la reactivación de la actividad sísmica del volcán Galeras, como la declaratoria de zona de desastre de buena parte de su territorio mediante el Decreto 4106 de 2005, y el reasentamiento de la población ubicada en la Zona de Amenaza Volcánica Alta (ZAVA) (figura 2). La Palabra de los indígenas, de los originarios de Jenoy, adquirió desde entonces fuerza y legitimidad jurídica y política al tenor de lo dispuesto en el artículo 246 de la Constitución política y la Ley 21 de 1991, presentándose, desde entonces, en asuntos territoriales relacionados con el uso del suelo y continuos conflictos de jurisdicciones.

3 En la Resolución N. ${ }^{\circ} 25$ del Ministerio de Agricultura de 1950, que disuelve el Resguardo de Jenoy (entonces Genoy), al igual que otras resoluciones emitidas por el mismo ministerio durante la época, se argumenta la falta de titulación colonial de los resguardos indígenas para acreditar su existencia. Esta condición jurídica exigida es, por demás, contraria al reconocimiento legal y expreso que la Corona española hizo de la propiedad territorial indígena, y que, en palabras de Fernando Mayorga, es suficiente para reivindicarlos como sus propietarios colectivos aun en la República, ya que esta hizo un reconocimiento expreso de la legislación colonial (Mayorga, 2013). Así lo delatan los textos legales que disuelven los resguardos, haciendo reconocimiento expreso de esa condición de hecho, la que desconocen por un tecnicismo jurídico, aún a sabiendas de que muchos de los títulos coloniales fueron desaparecidos mediante acciones dolosas de terceros interesados en la desintegración de los resguardos, tal y como está expresamente reconocido en los artículos 12 y 13 de la Ley 89 de 1890 . La Resolución antedicha concluye de la siguiente forma: "RESUELVE. PRIMERO: Declárese que el Resguardo de Genoy, situado en la jurisdicción del Municipio de Pasto, en el departamento de NARIÑO y cuyos linderos se transcriben a continuación, carece de la titulación necesaria para tener la calidad de resguardo de indígenas conforme a la ley 89 de 1890 y Decreto 74 de 1898, y que, sus terrenos no han salido del patrimonio del Estado" (Perugache, 2010). 


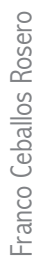

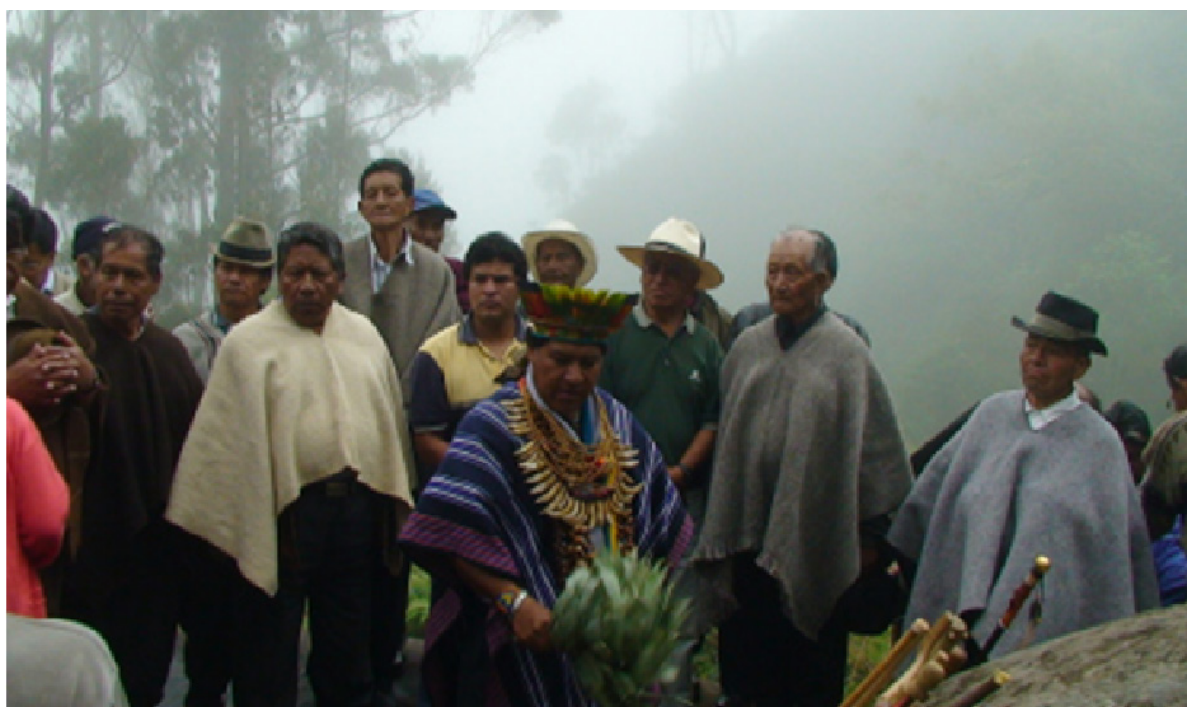

Figura 1. La posesión del Cabildo de Jenoy en 2008 Foto: Franco Ceballos Rosero.

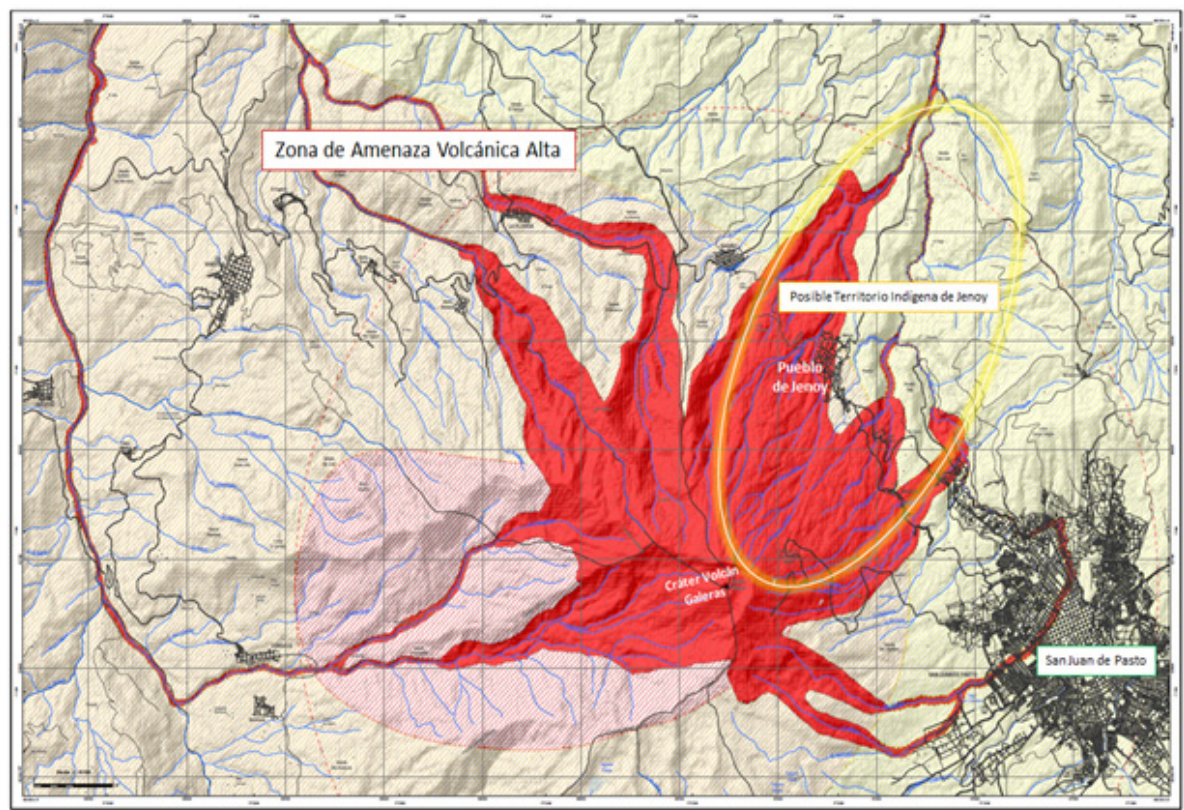

Figura 2. Mapa de la Zona de Amenaza Volcánica Alta. Territorio ancestral de los jenoyes

Fuente: https://www2.sgc.gov.co/sgc/volcanes/VolcanGaleras /Paginas/Mapa-de-amenaza.aspx 
El camino que siguió al renacimiento de la identidad étnica silenciada artificialmente hacia mediados del siglo XX ha sido difícil para los jenoyes, pues los ha situado, poco a poco, en una situación pasiva frente al gobierno nacional en sus asuntos fundamentales (censo poblacional, reconstrucción o no de su resguardo de origen colonial, el quehacer de sus autoridades), en buena medida por falta de una gestión adecuada por parte de sus autoridades tradicionales, particularmente en el periodo del exgobernador Aparicio Pasichaná (2009-2015), pero también por falta de acción y empoderamiento de la comunidad de su proceso de reconstrucción histórica. Este se fue adormeciendo conforme el impulso inicial del gobierno cedió, en particular en 2012 con la Ley 1523 sobre gestión del riesgo, que dejó sin efectos los decretos 4106 de 2005 y 3905 de 2008 hasta la sentencia de control de tutela de la Corte Constitucional T-269 en 2015, que reavivó el conflicto, aunque sin la visibilidad y fortaleza comunitaria inicial.

Junto a los jenoyes y sus resistencias identitarias y territoriales, desde un quehacer etnográfico solidario con su causa, indisciplinado (Haber, 2011) y enmarcado en propuestas metodológicas prácticas, vivenciales, vitales, plurales y dialógicas (Vasco, 2010, 2016; Mamián, 2000; De Sousa, 2011; Velasco, 2012), esta apuesta narrativa y ensayística presenta una perspectiva (etno) literaria del proceso de reconstrucción histórico del pueblo y territorio de Jenoy. Tejiendo y construyendo voces provenientes de una etnografia sin sujeto ni objeto de investigación más que el reconocimiento mismo, el aprendizaje recíproco y la solidaridad, esta propuesta narrativa explora, a través de diversas voces, la aspiración de los jenoyes a continuar viviendo en su territorio, donde tienen raíces tan profundas, que son, según afirman los Mayores (figura 3), imposibles de arrancar.

Voces como las de Don José Francisco Yaqueno (figura 4), Don Agustín Pianda, Doña Tulia Jenoy, Don Lisandro Martínez o Don Alberto Guevara, se entrelazan a partir de una suerte de trasmutación onírica sugerida por el Viejo Antonio como camino para el conocimiento. Por eso la historia que continúa "no me la contó 
nadie. Bueno, me la contó mi abuelo, pero él me advirtió que sólo la entendería cuando la soñara, asi que te cuento la historia que soñé y no la que me contó mi abuelo" (Marcos, 1995).

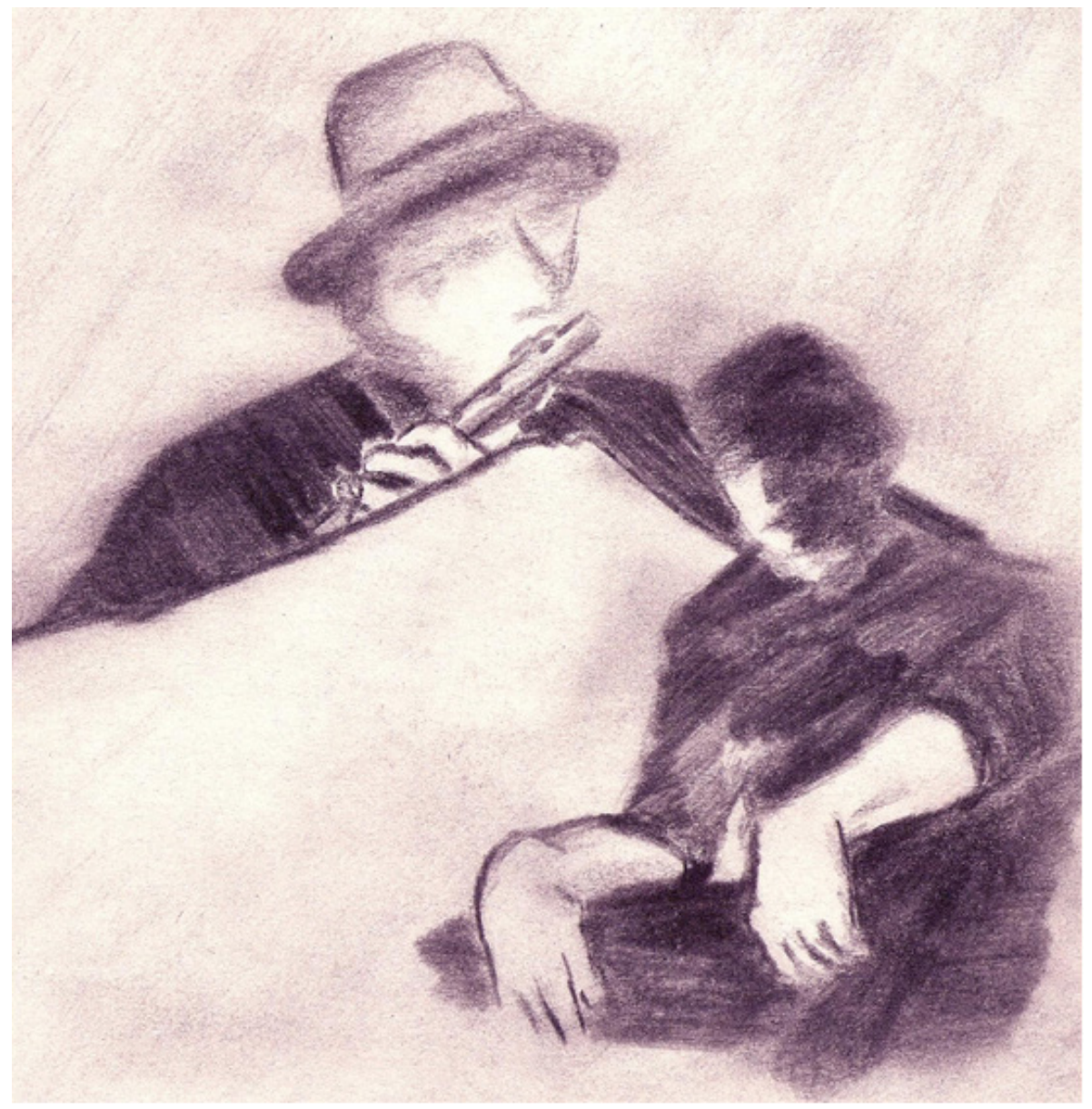

Figura 3. Los Mayores. Dibujo a carboncillo sobre papel bond de Franco Ceballos Rosero, 2006 


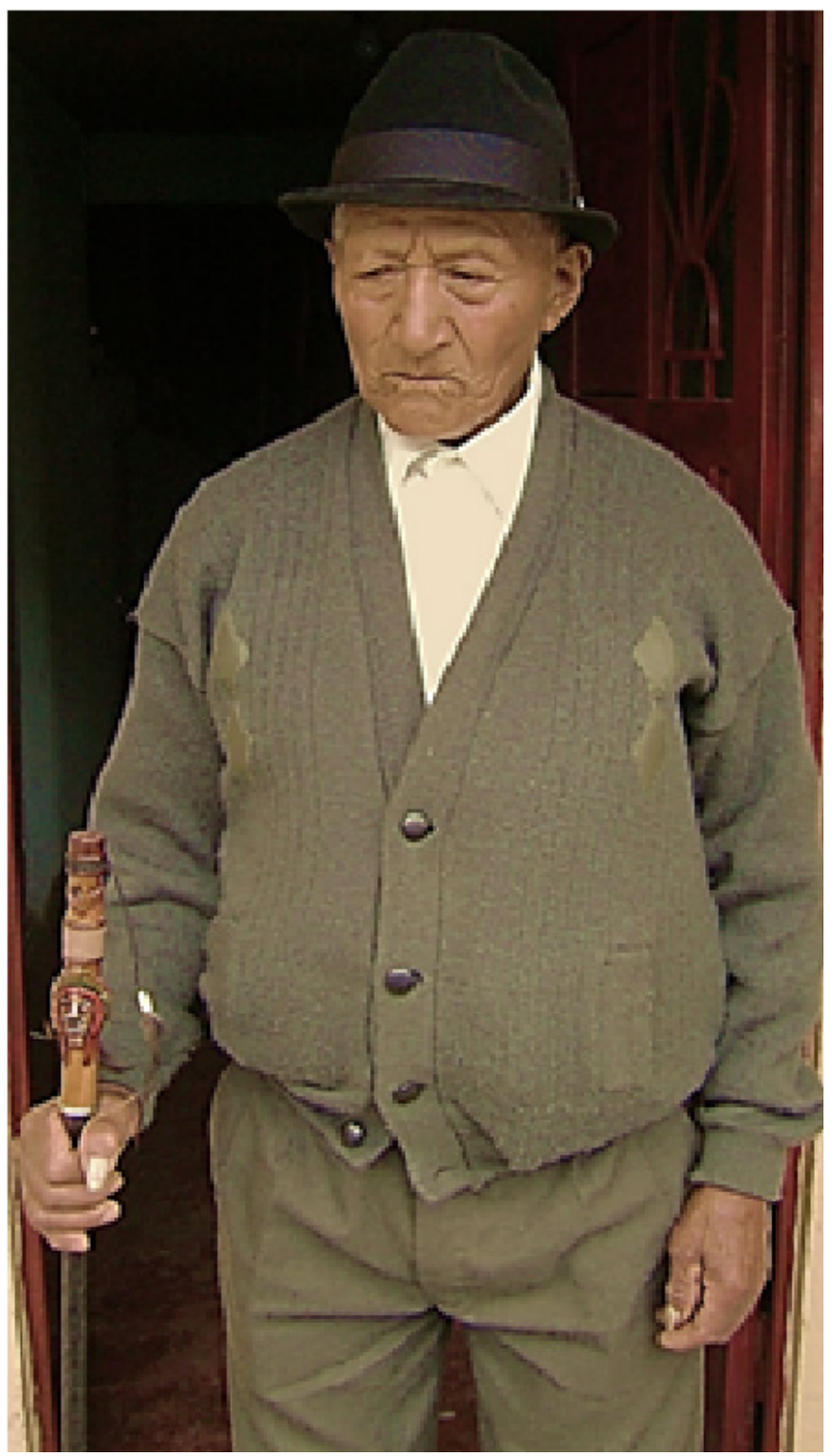

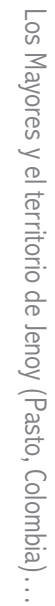

Figura 4. Don José Francisco Yaqueno, primer gobernador del Cabildo renaciente de Jenoy en 2008

Foto: Franco Ceballos Rosero. 


\title{
El quehacer etnográfico como propuesta etnoliteraria de resistencia
}

\author{
-¿Qué soñaste? / -Nada-le dije mientras \\ buscaba la pipa y el tabaco en la cartuchera. \\ / -Malo entonces. Soñando se sueña y se \\ conoce. Soñando se sabe-replicó el viejo \\ Antonio mientras volvía a la lenta caricia de la \\ lima sobre la lengua laminada de su machete. \\ / ¿Malo? ¿Por qué? -pregunté encendiendo ya \\ la pipa. / El viejo Antonio detuvo su tallar y, \\ después de comprobar el filo, dejó el machete \\ a un lado. Con sus manos y labios empezó un \\ cigarro y una historia. [...]-La historia que te \\ voy a contar no me la contó nadie...
}

Subcomandante Marcos, La historia de los sueños.

La etnografia es un proceso escritural de representación de los otros y sus formas de ser y estar en el mundo, proceso atado a la subjetividad del etnógrafo, que, si está en la orilla de la antropología, debe imprimir algunas características básicas a su quehacer: 1) la observación profunda de la realidad; 2) la sensibilidad al contexto, y 3) un análisis relacional complejo (Ingold, 2017), desde sus dos espacios concretos de acción, como trabajo de campo y retórica de la descripción del otro (Voirol, 2013), descripción en principio densa para la búsqueda de significaciones en y más allá de la razón y la ciencia (Hinojosa, 2010); en los espacios de la soledad creativa, donde también deben aflorar las empatías solidarias indispensables para el trabajo de campo (Ossola, 2013). Etnografia que se mueve como puente entre las ciencias sociales y la literatura en una suerte de lo que Alvarado Borgoño denomina "textualidad de frontera" (2014).

El quehacer etnográfico puede convertirse en una mera herramienta si se le considera solo un proceso de recolección de datos para generar descripciones más o menos ajustadas a las experiencias vividas para la aplicación de hermenéuticas racionales, 
y no un proceso de afectación mutua entre la realidad y el etnógrafo, durante el trabajo de campo propiamente dicho, así como durante el proceso de escritura, si el compromiso de partida es el de la solidaridad con los procesos históricos en los que se inserta el investigador, reconociendo su papel de agente transformador. ${ }^{4}$ Luis Guillermo Vasco llama a este compromiso solidario y metodológico recoger (2010) y desechar los conceptos en la vida (2016), camino de largo aliento en el que las palabras compartidas transgreden las fronteras epistemológicas de la ciencia como forma de conocimiento; pues su verdad está sujeta a las particularidades del arte, el mito y el sueño, en la perspectiva -por ejemplo- abordada por Carlos Castaneda desde Las enseñanzas de Don Juan en 1974 (2014); o mucho antes por cronistas como Pedro Cieza de León (2005), que hicieron de la ficción un ejercicio político para el sometimiento; o para el caso de los quillasingas en la actualidad, por Dumer Mamián (2000), quien a través de los quehaceres comunes sin teoría, teje los ecos de conversaciones vividas en una suerte de metodología del camino, a mitad de camino entre la creación literaria y académico-discursiva que renueva la memoria a partir de la acción conjunta y plural (Velasco, 2014); en el caso de la presente propuesta, desde la trinchera disciplinar del derecho, un tanto al margen de las discusiones teóricas sobre el problema de la representación, propios de la antropología (Ferreira y Arévalo, 2012), ya que el ejercicio profesional del derecho, la abogacía, es el de la representación, que implica necesariamente hablar por los otros ante escenarios jurídicos y políticos determinados.

La experiencia etnográfica es, en este sentido y desde una perspectiva jurídica de representación, una apuesta creativa que rebasa las fronteras científicas para ubicarse en el entramado del ser-para-el-otro (Levinas, 2001) en su causa y al amparo

\footnotetext{
Sobre este punto es importante retomar la discusión planteada por Mauricio Caviedes (2013), que tiene que ver con la condición indispensable de la existencia de la investigación solidaria si se ha de hablar de afectos y no de razones: la existencia de espacios de articulación construidos a lo largo de la trayectoria de las comunidades, ya que no puede forzarse este vínculo, pues este deviene del afecto, de la sensibilidad y el hombro a hombro investigador-comunidad. En todo caso, la reflexión planteada en el presente documento hace propio el ejercicio de la solidaridad como punto de partida en la relación investigador-comunidades, rompiendo las barreras epistemológicas impuestas desde los discursos cientificistas como los estructuralistas.
} 
del reconocimiento o apertura de territorios mentales y sensibles para la exploración del otro en la palabra, los caminos y los afectos, poniendo esta práctica al servicio de las reivindicaciones comunitarias y sociales desde el sur global y epistémico, que implican buscar alternativas de vida construidas desde el abajo del poder (Sousa, 2001; De Sousa, 2011); para el derecho mediante su uso alternativo (DeSouza, 2001; Rodríguez, 2013). Así, entonces, para que el uso de la etnografía por el derecho pueda proponerse como fuente y alternativa de reflexión, este debe plantearse desde las epistemologías del sur, desde la ficción como posibilidad comunicativa, pues de una ficción como de un sueño, dice Sabato, "se puede decir cualquier cosa, menos que sea una mentira" (Sabato, 1984).

El quehacer etnográfico deviene en creación (etno)literaria, entonces, cuando el etnógrafo descubre que su papel de comunicar sus experiencias de trabajo pasan por el sueño, por la ficción $\mathrm{y}$ el mito, pues tienen que ver con verdades que no se pueden expresar de otra forma. Esa apuesta creativa "no se construye únicamente con las razones de la cabeza, esas que sirven para demostrar teoremas, sino también -y sobre todo- con lo que Pascal llamaba "les raisons du coeur", las incomprensibles y contradictorias verdades del corazón" (Sabato, 1984). Eso es de cabeza y corazón, no de estudio.

La etnografía, vista así como una apuesta creativa literaria, puede catalogarse como etnoliteratura, si comprendemos por esta una categorización de la literatura producida por un determinado grupo social étnico o por quienes interactúan con estos, resaltando que lo étnico es la fuente de la que se nutren estas narraciones, que en todo caso deben ajustarse a lo que Camus señaló como los imperativos más difíciles de mantener en el oficio de la escritura: "la negativa a mentir respecto de lo que se sabe y la resistencia ante la opresión" (Camus, 1957). 


\section{La resistencia al desastre}

Después de la declaratoria de la zona aledaña del volcán Galeras como de desastre, mediante los Decretos 4106 de 2005 y 3905 de 2008, y su ratificación mediante la sentencia de revisión de tutela T-269-2015 de la Corte Constitucional, tras la interrupción que supuso la Ley 1523 de 2012 sobre gestión del riesgo, la situación del pueblo y territorio de Jenoy cambió radicalmente, al encontrarse inserto dentro de un proceso de reconstrucción histórica, identitario y territorial, tras más de sesenta años de desaparición jurídica y legal. De ser un corregimiento del municipio de Pasto, Jenoy ha pasado a ostentar la calidad de territorio indígena que tuvo hasta 1950, aunque la reticencia del Estado es grande para aceptar estos procesos reivindicatorios, ya que para la ciudad de Pasto significan su desmembración territorial con la consecuencial pérdida de control jurídico y político sobre los entornos ecológicos y agrarios, de los que se abastece diariamente.

Escuchemos algunas de las voces que pueblan la memoria colectiva para la resistencia frente a lo que los comuneros de Jenoy consideraron un proceso de desplazamiento forzado legal y " $\mathrm{hu}$ manitario". Aunque herramientas para el ejercicio académico de la representación propia del derecho, las narraciones que siguen pretenden solo privar del olvido todo aquello que le da fundamento a la terquedad de querer seguir siendo de Jenoy. Algunas de las voces más representativas provienen de Don José Yaqueno, Don Agustín Pianda, Don Lizandro Martínez, Don Adalberto Guevara, Doña Pascuala Criollo, Doña Tulia Jenoy, el profesor Anselmo Arteaga, Don Javier Quenan y otros tantos con los que se ha compartido la palabra, el camino y las huellas a seguir. 


\section{El Cabildo Antiguo}

I

Señor Ministro de la Economía Nacional, enero de 1939.

El suscrito Alcalde Mayor del Cabildo de la parcialidad de Genoy, junto a mis autoridades y comunidad, nos dirigimos a usted para que atienda nuestra súplica y se cumplan las leyes de la República para la división del Resguardo que por años incontables ha sido de nuestra posesión, ya que es oportuno que el progreso llegue a esta región. Hoy no existe en la parcialidad oposición de prácticamente nadie, ya que todos abrazamos las ventajas que trae la propiedad conforme nos lo hizo saber el doctor Aurelio Santacruz, que es hijo de este departamento y muy sabio.

Nuestro cabildo ruega a su señoría se apropie la partida en el presupuesto para la división de los Resguardos según dispone la Ley 19 de 1927, ya que es perjudicial seguir bajo el régimen de la Ley 89 de 1890 para la agricultura y la ganadería del pueblo, pues han sido los gobiernos de Cabildos un obstáculo fuerte para el progreso del país.

Le ruego me comunique la decisión del gobierno para informar y preparar al pueblo para los trabajos a que haya lugar.

Darío Criollo, Alcalde Mayor. ${ }^{5}$

5 Después de varias pesquisas archivísticas en Pasto y Bogotá, el equipo de investigaciones del Pueblo Quillasinga descubrió que la mayoría de los documentos remitidos por parte de sus ancestros al gobierno central fueron redactados por tres abogados oriundos de la ciudad de Pasto: Aurelio Santacruz, de la Universidad de Nariño; Adalberto Zarama Delgado, de una universidad de Bogotá, y un tal Antonio Muñoz de Ayala que dizque se había titulado en Francia. A los tres, entre 1930 y 1952, los contrató el Ministerio de la Economía para explicar a los indígenas del sur las ventajas de la propiedad privada y asegurar su aquiescencia para la división del resguardo. 
Don José tomó la palabra en medio de la noche profunda, cuando ya todos nos despedíamos. Yo me acuerdo... -dijo con su voz fuerte y dulce a la vez, mientras encendía un pielroja esperando que todos volviéramos a sentarnos junto a las brasas humeantes. -Yo me acuerdo de Don Darío Criollo y sé qué fue lo que pasó en esa época antes de esta. Él jamás estuvo de acuerdo con que nuestro territorio dejara de ser Resguardo y nuestras autoridades Cabildo, pero no podía hacer nada y le tocó acatar las decisiones de la mayoría de parcialistas, que habian sido convencidos de las ventajas de tener títulos y préstamos. Pero yo me acuerdo de que Don Darío sabía decir que si perdíamos el Cabildo pronto nos iban a acabar, y que los Delgados y Santacruces se iban a apoderar de las mejores tierras, como pasó, pues muchos de los comuneros después de que les hicieron los títulos de propiedad vendieron rápido, y así mismo se quedaron sin nada y se fueron a Pasto a vivir y trabajar en la construcción y los oficios, desapareciendo para siempre de nuestra comunidad.

Yo me acuerdo de Don Darío Criollo porque de él aprendí muchas cosas, sobre todo del trabajo de la agricultura, pues mi papá me sabía mandar con él, porque era buen comunero y yo no era ningún haragán y podía ganarme unos pesos. De él aprendí lo que sé de sembrar y de guiar, porque durante años me contó sus historias mientras trabajábamos; por eso, antes de morir me encargó la Vara de Justicia que tuvo cuando se acabó el Cabildo, y que se las presento aquí, para aportar al pensamiento de la comunidad.

\section{La Comunidad, la Vida, la Resistencia}

\section{III}

Eso fue en el 2005, en octubre o noviembre más o menos, después de una sacudida del Galeras que dejó a Pasto lleno de ceniza. Una 
señora de apellido Calvache hizo un estudio científico que dijo que todo lo que pueden ver ustedes es zona de desastre, y aparecieron los policías y el ejército a dizque llevarnos a un lugar seguro, que después llamaron los Albergues, allá en Puyitopamba.

Eso llegaron golpeando y alarmando a todos, diciendo que esto era zona de desastre, y que teníamos que irnos para salvar nuestras vidas. Cómo no sería el impacto que varios Mayores se murieron del espanto de ver tanto policía y ejército estorbando en el pueblo. Nosotros nos negamos a irnos, pues como originarios de acá sabemos cómo es el Galeras, y aunque fue difícil, no nos dejamos sacar por las órdenes del presidente Uribe en ese entonces. Mi mamá, que ya está bien mayor, en ese día sacó el berraquillo ${ }^{6}$ de mi papá y se plantó frente al Comandante de la Policía, cosa que todos cogimos valor y los mandamos a ellos a los albergues. ${ }^{7}$

\section{IV}

Cuando la reunión se fue terminando, el consenso general apuntó a que era menester estudiar la posibilidad de retomar las autoridades del Cabildo para enfrentar al gobierno y el Decreto 4106. Según explicaron el profesor Dumer y su equipo de trabajo del IADAP, la Constitución Política y las leyes 89 de 1890 y 21 de 1991 permitían recuperar la identidad perdida mediante un ejercicio autónomo de organización comunitaria. Seguir los rastros, explicó el profesor a todos los Mayores presentes, es la clave para desatar la historia para la resistencia.

-Disculpen -dijo una de las Mayores que había permanecido en silencio durante toda la reunión, esperando seguramente el momento oportuno para aportar. -Yo tengo una historia que contarles,

6 Un berraquillo es una vara hecha de buena madera que tiene varios propósitos, siendo el principal la defensa personal del comunero que lo carga, tanto del posible ataque de perros bravos, como de otros comuneros y ciudadanos.

7 Los jenoyes recordaron, días más tarde, que conforme Doña Tulia Jenoy se había plantado frente a los policías a las órdenes de Uribe, así había pasado en el tiempo antiguo contra las fuerzas de Simón Bolívar, que dicen intentó llegar a Pasto por el camino de Jenoy, siendo detenido por una mujer, una chichera, que logrando cargar una piedra enorme, se la arrojó al General Valdés que encabezaba las huestes de Bolívar, matándolo y haciendo que los demás comuneros tomaran valor para rechazar con palos, piedras y azadones a las tropas antirrealistas. 
que me la contó mi mamá abuela cuando era yo una niña y había Cabildo y Resguardo. Es la historia del Juan Rayo, y creo que nos sirve, pues esa historia está escrita en la piedra que descubrió el profesor Romualdo Criollo allá en el Sitio Tomates, en Aguapamba, camino al Galeras.

Contaba mi mamá abuela que hubo un tiempo muy triste para los indigenas de Jenoy, ya que se encontraban esclavizados en las haciendas de los ricos, trabajando por casi nada de sol a sombra hasta los domingos. Entonces - contaba mi abuela -un día dizque llovió como si el diluvio se repitiera. Todos los indígenas que estuvieron en el pueblo se encampanaron donde pudieron mientras los rayos y truenos no dejaban de suceder.

Decía mi mamá abuela que cuando la lluvia fue más intensa cayó un rayo en el centro del pueblo, y que apenas cayó se escuchó un niño de pecho llorar con toda la fuerza. Una indigena dizque corrió al lugar donde cayó el rayo y encontró a un niño chiquito 1lorando, al que abrazó con fuerza y se lo llevó a su casa seguida de la romería de la gente. Cuando amainó la lluvia dizque revisaron al guagua que había aparecido donde cayó el rayo y dizque encontraron que traía escrito por su cuerpo que donde había caído el rayo el dueño era el originario de Jenoy. Y dizque el niño creció rápido y se volvió un líder que ayudó a que la gente se sacudiera de la esclavitud y nombrara Cabildo para defender a la comunidad. El niño dizque se llamaba Juan Criollo. Por eso quedamos los criollos por todo ello y las escrituras.

\section{$\mathbf{V}$}

Estos choclos que estamos comiendo son de la chagra que tengo en San Juan Pamba, detrás de la iglesia. Allá se da un maíz bien bueno y no se necesita nada de químicos, porque cuando el Galeras arrojó cenizas hace unos diez años esto quedó bendito para sembrar. ¡Lástima que nadie quiere sembrar para vivir! ¡Solo para lo de la casa! Eso antes los Mayores a punta de trabajar la tierra sacaron 
adelante este pueblo, trazaron caminos, levantaron casas, cavaron aljibes, construyeron la iglesia, el cementerio, el acueducto y la Casa Mayor. Ahora los jóvenes se van a la universidad o a trabajar en la construcción, en vigilancia y otros oficios, porque la agricultura ya no es rentable.

El queso lo trajeron los amigos de Mocondino, porque allá igual pasó con la agricultura, y prefieren vivir teniendo unas vaquitas para sacar leche que sembrar a pérdida, porque la gente de la ciudad no comprende el trabajo que hay que hacer para sembrar, y creen que lo único que hay que tener en cuenta es su bolsillo. La leche es renta, es fija y la inversión no es tanta como para sacar un bulto de papas o de habas. ¿Está todo bien? Me alegro, profesores, porque tienen que comer bien bueno antes de salir a caminar hacia el Camino Viejo que queda como a tres horas hacia la cima del Galeras. Allá arriba tengo un terrenito que lo tengo bien bonito porque es un nacedero de agua que cuido por una deuda de vida con un espíritu de allá arriba que una vez me encontré paseando con Don Darío Criollo. Ojalá que en la caminata ustedes puedan sentir y ver al Manuel, el espíritu que habita en lo alto del Galeras, cuidando la ciudad de oro que existe debajo de este territorio. Si es así, seguro que me dan la razón de lo que le digo: que la zona de desastre es una mentira, un pretexto para buscar esas riquezas sin que nos demos cuenta. Yo he visto japoneses y alemanes rondando el Galeras, solo que nadie me cree.

\section{VI}

Pues con Don Adalberto Guevara y mi persona, Don Agustín Pianda, tenemos el grupo Los Amigos, y con la música hemos ido a todas partes, porque les gusta mucho lo que hacemos. Para esta reunión preparamos un temita, el Himno al Galeras, para que todos cojamos fuerzas para defender lo que nos han dejado nuestros Mayores más antiguos, y que está escrito en las piedras que están allá en Aguapamba. Este tema dice que como el volcán Galeras no hay otro territorio mejor dónde vivir, pues hasta sus aguas son 
medicinales. Tenemos lo frío para la papa, el olloco, las habas; lo templado para el maíz, sobre todo, y lo caliente para el plátano, la caña... O las naranjas, que se dan buenas allá en la Chagra de Don Javier Quenan en Puyitopamba. Ahí les va:

Pero qué linda mirada, Que tiene el Taita Galeras, Cuando el viento sopla duro

Él hace lindos cantares...

(Los Amigos de Jenoy, 2011)

\section{VII}

Yo cuando supe que Don Aparicio iba a ser el gobernador no me dio buena espina, y ahora lo venimos a confirmar. En el Cabildo no dejó ni un archivo de lo que hizo, de la plata que recibió, de los proyectos que tuvo a su cargo... Nada. A nosotras nos hizo la guerra y nos fue sacando de las autoridades, por eso hicimos el grupo de Las Mujeres e hicimos cosas por nuestra cuenta, como la Chagra de Medicina, o la escuela de tejidos. La esposa del profesor Dumer, Doña Lucy, estuvo todo el tiempo con nosotras, a veces con más constancia, a veces alcanzadas por los oficios y responsabilidades que son muchas. Porque aquí donde me ven, profesores, yo todavía trabajo vendiendo frutas y verduras en Pasto, cerca de la Iglesia de la Sagrada Familia para mantenerme ocupada, llevar la comida a la casa y ayudar a los míos, porque eso sí enseñaron las antiguas: ayudar al vecino, al compadre... Pero ese gobernador se portó mal, sobre todo con los Mayores. No ve al pobre Don José cómo lo fue sacando del todo del Cabildo hasta que lo aburrió.

\section{VIII}

El problema del reasentamiento acá en Jenoy pasa porque ni Don Aparicio Pasichaná, ni Don Henry Criollo hasta ahora han 
solicitado la Consulta Previa para ver qué pasa con nuestro territorio. Yo hace rato les dije a las autoridades que no debemos hablar con nadie del gobierno si no es en la Consulta Previa para que quede en un documento lo que ha de pasar en adelante con nosotros, porque la incertidumbre sigue, porque otra vez volvió la zona de desastre por culpa de la Corte Constitucional cuando ya creímos que le habíamos ganado la pelea al gobierno. Otra vez están con lo de la zona de desastre y molestando a todos los que hemos hecho mejoras a nuestras casas porque dizque no tenemos el permiso, como si necesitáramos que alguien nos dé permiso para decidir sobre nuestra tierra.

Sé que los Mayores, Don Agustín y Don Lizandro, estuvieron con usted tratando de solicitar la Consulta Previa, pero les fue difícil porque el gobernador Pasichaná se opuso por celos de poder. Hoy que parece que no hubiéremos hecho nada después de tantos años, volvemos a lo mismo, sin haber recuperado nuestro resguardo por desidia de las autoridades, que se concentraron en recoger y gastarse unos pocos pesos por ahí.

\section{IX}

Dizque zona de desastre

De gran peligrosidad

Aquí el único desastre

Es la tal autoridad.

La raza de los jenoyes

Es dura como el granito Aquí no hay gente tan mansa

Que salga de la manito.

(Arteaga, 2007) 
El Galeras es persona, profesores, tal y como su Guardián, el Manuel, como llamaba Don Juanito Bastidas, el médico del pueblo de Nariño que estaba compactado con los espíritus del Volcán y curaba con tomas de aguas medicinales. Y como persona que es, el Galeras tiene derechos, como el de estar tranquilo allá arriba, cosa de la que solo nosotros sabemos. Por eso cuando el Galeras se despierta y sacude la tierra y las conciencias (como nos pasó a nosotros), sabemos cómo calmarlo para que siga siendo nuestro protector. Los científicos no nos comprenden, y hasta se burlan de nosotros, pero eso cuando el Galeras empieza a disgustarse hay que llevar en procesión desde el pueblo a la Virgen del Rosario Chiquita, que también es persona, para que su poder apacigüe a nuestro Taita, nuestro Papá. Eso, jóvenes profesores, se lo comprende con la cabeza y el corazón en la palabra, el camino y la amistad, no con estudio.

\section{Conclusiones}

A trece años de la declaratoria del territorio aledaño al Volcán Galeras como de desastre, los problemas para los habitantes del territorio de Jenoy no han cesado, pues aparte del problema jurídico y politico que enfrenta a la comunidad con el Estado por el control territorial y vital, aparecieron los enfrentamientos internos relacionados con la dirección de la resistencia, pues el impulso inicial se fue diluyendo conforme el empuje del Estado cedió para convertirse en una simple política de compra de predios sin mayor resultado con los propósitos de las políticas adoptadas en los Decretos 4106 de 2005 y 3905 de 2008.

Pese a que el panorama no es el mejor en su lucha contra el Estado por la declaratoria de zona de desastre y la politica del reasentamiento, la comunidad del pueblo y territorio de Jenoy ha reactivado y legitimado todo aquello que se creyó extinto con la Resolución 25 del Ministerio de Agricultura en 1950 y hoy es la plataforma política 
y jurídica para su decisión de continuar viviendo donde siempre han vivido y descansan sus ancestros, sus mayores, sus espíritus y naturaleza. En medio de esos rostros y rastros por andar se vislumbran los fundamentos de lo que hoy se conoce a nivel jurídico como los derechos de la naturaleza, pues es evidente que los jenoyes no solo luchan por su pervivencia, sino por la de la totalidad del territorio que habitan junto a seres naturales y espirituales que son considerados personas.

\section{Referencias}

Arteaga, A. (2007). Coplas. Jenoy, Colombia: inédito.

Camus, A. (1957). Discurso de aceptación del Nobel. Recuperado de http:// biblio3.url.edu.gt: http://gatopardo.blogia.com/2009/103101-albert-camusdiscurso-de-aceptacion-del-premio-nobel-de-literatura-ano-1957.php

Castaneda, C. (2014). Las enseñanzas de Don Juan, una forma de conocimiento yaqui. México: Fondo de Cultura Económica. Recuperado de https:// vivelatinoamerica.files.wordpress.com/2017/10/las-ensec3b1anzas-de-donjuan.pdf

Caviedes, M. (2013). Metodologias que nos avergüenzan: la propuesta de una investigación en doble vía y su efimera influencia. Universitas Humanística, 75, 37-61.

Cieza-de-León, P. (2005). Crónica del Perú. El señorio de los Incas. Caracas: Fundación Biblioteca Ayacucho. Recuperado de http://www.biblioteca.org. ar/libros / 211665.pdf

De Sousa, B. (2011). Epistemologías del Sur. Utopía y Práxis Latinoamericana, 16(54), 17-39.

DeSouza, M. (2001). El uso alternativo del Derecho. Génesis y evolución en Italia, España y Brasil. Bogotá: Facultad de Derecho, Ciencias Políticas y Sociales, Universidad Nacional de Colombia - ILSA. 
Ferreira, M. y Arévalo, D. (2012). Escribir al otro: alteridad, literatura y antropología. Bogotá: Universidad de los Andes. Recuperado de https:/ / ebookcentral.proquest.com/lib/ucooperativasp/reader. action?ppg=1\&docID=3212191\&tm $=1521398898614$

Haber, A. (2011). Nometodología payanesa: notas de metodología indisciplinada. Revista Chilena de Antropología, (23).

Hinojosa, O. (2010). Ficción histórica y realidad literaria. Bern: Peter Lang. Recuperado de https://books.google.com.co/books?id=15Ly-nlvwzYC\&pg=PA $59 \& d q=$ descripci\%C3\%B3n+densa + pdf\&hl=es\&sa=X\&ved=0ahUKEwjYk56H 3PPZAhVpmeAKHZfGDscQ6AEILDAB\#v=onepage\&q=descripci\%C3\%B3n\%20 densa\%20pdf\&f=false

Ingold, T. (2017). Suficiente con la etnografía. Revista Colombiana de Antropología, 53(2), 143-159.

Levinas, E. (2001). Ensayos para pensar en otro. Valencia: PreTextos.

Los Amigos de Jenoy. (2011). Himno al Galeras. Jenoy, Colombia: Video de Jorge Perugache. Recuperado de https: / / www.youtube.com/watch?v=4OjsNomMuLO

Mamián, D. (2000). Rostros y rastros de un camino por andar. Mopa Mopa, 75-88.

Marcos, S. (1995). La historia de los sueños. Recuperado de http://palabra. ezln.org.mx/comunicados /1995/1995_12_25.htm

Ossola, M. (2013). La autoridad etnográfica interpelada. Universitas Humanística, 75, 63-80.

Perugache, J. (2010). Volver a Mirichir. Mopa Mopa, (20), 9-23.

Rodríguez, L. (2013). El uso alternativo del derecho. Génesis y evolución. Amicus Curiae (Segunda Época), 2(1), 1-13. 
Sabato, E. (1984). Discurso Premio Cervantes. RTVE Radio Televisión Española. Recuperado de http:/ /www.rtve.es/rtve/20141022/discurso-ernesto-sabatopremio-cervantes-1984/1033960.shtml

Santos, B. (2010). Refundación del Estado en América Latina. Perspectivas desde una etimología del sur. Lima: Instituto Internacional de Derecho y Sociedad. Recuperado de http://www.boaventuradesousasantos.pt/media/ Refundacion\%20de1\%20Estado_Lima2010.pdf

Sousa, B. d. (2001). El caleidoscopio de las justicias en Colombia. Bogotá: Colciencias - ICAH.

Vasco, L. G. (2010, septiembre). Recoger los conceptos en la vida: una metodología de investigación solidaria. Recuperado de http://luguiva.net

Vasco, L. G. (2016). Desechar los conceptos en la vida. Recuperado de Luguiva.net: http://www.luguiva.net/admin/pdfs /DESECHAR\%20LOS\%20 CONCEPTOS\%20EN\%20LA\%20VIDA.pdf

Velasco, Á. (2012). Cómo llegar al presente: recuperación de la memoria para las luchas de hoy. Mopa Mopa, 21(21), 145-155.

Velasco, Á. (2014). Poligrafia Social. Recuperado de https://prezi.com/: https:// prezi.com/spoiuplmehyx/poligrafia-social-diplomado-de-metodologia-de-lainvestigacion/

Voirol, J. (2013). ¿Cómo practicar la etnografia? Universitas Humanística, 75, 81-104.

\section{Cómo citar este artículo}

Ceballos Rosero, F. (2018). Los Mayores y el territorio de Jenoy (Pasto, Colombia): quehacer etnográfico y etnoliteratura de resistencia. Universitas Humanistica, 86, 197-218. https://doi.org/10.11144/Javeriana.uh86.mtjp 